\title{
Hypoxia-inducible factor 1 and VEGF upregulate CXCR4 in glioblastoma: implications for angiogenesis and glioma cell invasion
}

\author{
David Zagzag1,2,3,4,5, Yevgeniy Lukyanov ${ }^{1,2}$, Li Lan ${ }^{1,2}$, M Aktar Ali ${ }^{1,2}$, Mine Esencay ${ }^{1,2}$, \\ Olga Mendez ${ }^{1,2}$, Herman Yee ${ }^{2,5}$, Evelyn B Voura $^{1,4}$ and Elizabeth W Newcomb ${ }^{2,5}$ \\ ${ }^{1}$ Microvascular and Molecular Neuro-Oncology Laboratory, New York University School of Medicine, New \\ York, NY, USA; ${ }^{2}$ Department of Pathology, New York University School of Medicine, New York, NY, USA; \\ ${ }^{3}$ Division of Neuropathology, New York University School of Medicine, New York, NY, USA; ${ }^{4}$ Department of \\ Neurosurgery, New York University School of Medicine, New York, NY, USA and ${ }^{5}$ New York University \\ Cancer Institute, New York University School of Medicine, New York, NY, USA
}

\begin{abstract}
Hypoxia and hypoxia-inducible factor-1 (HIF-1) play a critical role in glioblastoma multiforme (GBMs). CXCR4 is involved in angiogenesis and is upregulated by HIF-1 $\alpha$. CXCR4 is a chemokine receptor for stromal cell-derived factor-1 (SDF-1) $\alpha$, also known as CXCL12. We hypothesized that CXCR4 would be upregulated by hypoxia in GBMs. First, we investigated the expression of HIF- $1 \alpha$ and CXCR4 in GBMs. CXCR4 was consistently found colocalized with HIF- $1 \alpha$ expression in pseudopalisading glioma cells around areas of necrosis. In addition, angiogenic tumor vessels were strongly positive for CXCR4. Next, we tested the in vitro effect of hypoxia and vascular endothelial growth factor (VEGF) on the expression of CXCR4 in glioma cell lines and in human brain microvascular endothelial cells (HBMECs). Exposure to hypoxia induced significant expression of CXCR4 and HIF-1 $\alpha$ in glioma cells, whereas treatment with exogenous VEGF increased CXCR4 expression in HBMECs. We also transfected U87MG glioma cells with an HIF-1 $\alpha$ construct and observed that CXCR4 was upregulated in these cells even in normoxic conditions. We then used a lentivirus-mediated shRNA expression vector directed against HIF-1 $\alpha$. When exposed to hypoxia, infected cells failed to show HIF- $1 \alpha$ and CXCR4 upregulation. We performed migration assays under normoxic and hypoxic conditions in the presence or absence of AMD3100, a CXCR4 inhibitor. There was a significant increase in the migration of U87MG and LN308 glioma cells in hypoxic conditions, which was inhibited in the presence of AMD3100. These studies demonstrate the critical role played by hypoxia and CXCR4 in glioma cell migration. Based on these studies, we suggest that hypoxia regulates CXCR4 in GBMs at two levels. First, through HIF-1 $\alpha$ in the pseudopalisading tumor cells themselves and, secondly, by the VEGF-stimulated angiogenic response in HBMECs. We believe this knowledge may lead to a potentially important two-pronged therapy against GBM progression using chemotherapy targeting CXCR4. Laboratory Investigation (2006) 86, 1221-1232. doi:10.1038/labinvest.3700482; published online 30 October 2006
\end{abstract}

Keywords: angiogenesis; CXCR4; gliomas; hypoxia; hypoxia-inducible factor-1; migration; stromal cell-derived factor- $1 \alpha$; vascular endothelial growth factor

Angiogenesis is required for the sustained growth and progression of gliomas. ${ }^{1}$ Glioblastoma multiforme (GBMs), the most malignant of the gliomas, display significant angiogenesis that is partly linked to hypoxia, ${ }^{1}$ a universal characteristic of malignant

Correspondence: Dr D Zagzag, MD, PhD, Division of Neuropathology, Department of Pathology, New York University Medical Center, 550 First Avenue, New York, NY 10016, USA.

E-mail: dz4@nyu.edu

Received 13 April 2006; revised 9 May 2006; accepted 9 June 2006; published online 30 October 2006 neoplasms. ${ }^{2}$ Hypoxia-inducible factor-1 (HIF-1) is a transcription factor that regulates $\mathrm{O}_{2}$ homeostasis in response to changes in $\mathrm{O}_{2}$ levels in normal and tumor tissues. ${ }^{3,4}$ HIF-1 is a ubiquitously expressed and highly conserved heterodimeric basic-helixloop-helix-PAS transcription factor composed of an $\alpha$ - and a $\beta$-subunit. ${ }^{4}$ As cellular $\mathrm{O}_{2}$ concentration decreases, levels of the HIF- $1 \alpha$ subunit increase, and this determines the level of HIF-1 activity. ${ }^{4}$ Under hypoxic conditions, HIF-1 activates a large battery of genes whose protein products function either to increase $\mathrm{O}_{2}$ availability or to allow metabolic 
adaptation of cells to $\mathrm{O}_{2}$ deprivation within their microenvironment. These genes contain hypoxic response elements (HREs) and include genes such as vascular endothelial growth factor (VEGF), a highly potent cytokine known to promote angiogenesis. ${ }^{5-7}$ As a result, HIF- $1 \alpha$ and its signaling pathway have become targets for cancer chemotherapy aimed at inhibiting angiogenesis. ${ }^{8-14}$

We and others have correlated increased HIF-1 $\alpha$ expression in tumors with advanced disease stage, increased angiogenesis and poor prognosis. ${ }^{15-19}$ GBMs are noted for being one of the most highly angiogenic solid tumors. ${ }^{1}$ In GBMs, HIF- $1 \alpha$ is highly expressed in pseudopalisading tumor cells adjacent to necrosis, suggesting that the pattern of expression of HIF- $1 \alpha$ in GBMs is modulated, at least in part, by tumor oxygenation. VEGF expression is also present in pseudopalisading cells. ${ }^{20,21}$ The colocalization of HIF-1 $\alpha$ with VEGF expression suggests a potential pathway for angiogenesis mediated by VEGF. Thus, it is likely that hypoxia induces HIF- $1 \alpha$ expression in GBMs, which in turn activates VEGF gene transcription, leading to increased VEGF production and angiogenic activity.

Another gene reported to be positively regulated by HIF- $1 \alpha$ via an HRE sequence in its $5^{\prime}$ end is CXCR4. ${ }^{22,23}$ CXCR4, a chemokine receptor for stromal cell-derived factor 1 (SDF-1) $\alpha^{24,25}$ is an important molecule associated with tumor progression and metastatic spread of a variety of different malignancies, including lung, pancreas, and breast. ${ }^{26-30}$ Several studies investigated the expression and functional role of CXCR4 in gliomas. ${ }^{31-35}$ For example, CXCR4 was shown to play a critical role in glioma invasion. ${ }^{36}$ Given that HIF- $1 \alpha$ upregulation occurs in pseudopalisading cells around the area of necrosis in gliomas overlapping with the expression patterns for VEGF and CXCR4, ${ }^{1,15,31}$ we wished to test the hypothesis that hypoxia may independently upregulate CXCR4 expression in glioma cells.

We show that CXCR4 levels correlate with HIF-1 $\alpha$ levels in human GBM specimens and is expressed in angiogenic tumor vessels in vivo. CXCR4 expression was significantly induced in glioma cells after exposure to hypoxia in vitro. CXCR4 could also be upregulated in normoxic U87MG glioma cells following transfection and overexpression of the HIF-1 $\alpha$ gene. Glioma cells infected with a lentivirusmediated shRNA expression vector directed against HIF- $1 \alpha$ failed to upregulate HIF- $1 \alpha$ and CXCR4 when exposed to hypoxia. Migration studies in hypoxic conditions in the presence of AMD3100, a CXCR4 inhibitor, resulted in a significant decrease in migration of glioma cells. These studies demonstrate that CXCR4 plays an important role in glioma cell migration. In addition, CXCR4 expression was induced in human brain microvascular endothelial cells (HBMECs) after exposure to VEGF. Based on these studies, we suggest that hypoxia regulates CXCR4 in GBMs at two levels. First, through HIF-1 $\alpha$ in the pseudopalisading tumor cells themselves and, secondly, by the VEGF-stimulated angiogenic response in HBMECs. We believe this knowledge may lead to a potentially important two-pronged therapy against GBM progression using chemotherapy targeting CXCR4.

\section{Materials and methods}

\section{Clinical Information}

This study was conducted under a protocol approved by the Institutional Review Board of New York University School of Medicine. In total, 18 GBMs classified according to WHO criteria were studied. ${ }^{37}$ There were 11 female and 7 male patients. The age range was from 34 to 80 years. In 11 of the 18 cases examined in this study, cerebral tissue remote from the tumors, that is, non-tumor brain tissue, was present and served as control tissue for the immunohistochemical studies.

\section{Immunohistochemistry}

Immunohistochemistry for HIF- $1 \alpha$ and CXCR4 was performed as previously described. ${ }^{15,23,31}$ All formalin-fixed, paraffin-embedded human tissue specimens were obtained from standard surgical operations. Briefly, formalin-fixed, paraffin-embedded tissue was prepared using conventional histological methods. Serial sections $(6 \mu \mathrm{m})$ were cut from each paraffin block. One section was stained with H\&E for histological assessment. Serial sections were immunostained for CXCR4 or HIF- $1 \alpha$. Immunohistochemistry was performed using a computer-controlled automated immunostainer, NexES (Ventana Medical Systems, Tucson, AZ, USA). Slides were deparaffinized by three washes of xylene, followed by washes through graded alcohols (100-70\%) into phosphate-buffered saline. Antigen retrieval (AR) was performed in boiling $0.01 \mathrm{M}$ citrate buffer, $\mathrm{pH} 6$, for the appropriate amount of time, in minutes, as indicated. For CXCR4, we used a goat polyclonal, diluted 1:25, AR10 (Santa Cruz Biotechnology Inc., Santa Cruz, CA, USA; clone G-19) and a mouse monoclonal, diluted 1:100, AR45 for HIF-1 $\alpha$ (Lab Vision Corp., Fremont, CA, USA; clone $\mathrm{H} 1 \alpha 67)$. All primary antibodies were incubated at room temperature overnight and then detected using an avidin-biotin complex with 3,3 diaminobenzidine (DAB) as the chromogen. For CXCR4, we used a biotinylated secondary antibody, rabbit anti-goat (Vector Laboratories, diluted 1:100, 32 min incubation) and a peroxidase-labelled antimouse secondary antibody conjugated to fluorescein-labelled tyramide reacting against an antifluorescein peroxidase (Dako CSA II Biotin-free Tyramide Signal Amplification System) for HIF- $1 \alpha$. Negative controls consisted of incubation of the 
tissue section without primary antibody but with isotype-specific immunoglobulins.

\section{Histological Assessment}

Two pathologists (DZ and HY) independently evaluated the immunostaining results. When an evaluation differed, the final decision was made by consensus. The immunohistochemical analysis of HIF- $1 \alpha$ and CXCR4 expression was scored as follows: - , no staining; + , staining of less than $1 \%$ of cells; ++ , staining of less than $10 \%$ of cells; +++ , staining of $10-50 \%$ of cells; ++++ , staining of greater than $50 \%$ of cells. In each case, immunoreactivity for CXCR4 and HIF- $1 \alpha$ was scored separately for tumor cells, vascular cells, or adjacent normal brain tissue.

\section{Cells and Reagents}

The human glioma cell line LN308 (kindly provided by Dr Frank Furnari from the Ludwig Institute for Cancer Research, UCSD) and the U87MG cell line, purchased from the American Type Culture Collection (ATCC; Manassas, VA, USA) were used. Cell lines were cultured in $5 \% \mathrm{CO}_{2}$ and $95 \%$ humidified atmosphere air at $37^{\circ} \mathrm{C}$ in Dulbecco's modified Eagle's medium (DMEM; Gibco BRL, Grand Island, NY, USA). The medium was supplemented with $10 \%$ fetal bovine serum (FBS; Atlanta Biologicals, Norcross, GA, USA), 1\% penicillin and streptomycin, and $2 \mathrm{mM}$ glutamine (Gibco BRL). Glioma cell lines were split every 3 days to ensure logarithmic growth. HBMECs were purchased from Cell Systems (Kirkland, Washington) and grown in complete growth medium (Cell Systems). For hypoxic exposure, cells were placed in a sealed Modular Incubator Chamber (Billups-Rothenberg Inc., Del Mar, CA, USA) flushed with $1 \% \mathrm{O}_{2}, 5 \% \mathrm{CO}_{2}$, and $94 \% \mathrm{~N}_{2}$.

AMD3100, a bicyclam, is a nonpeptide CXCR4 inhibitor. ${ }^{38}$ The stock solution was made in PBS $(5 \mathrm{mg} / \mathrm{ml})$ and kept at $4^{\circ} \mathrm{C}$. AMD3100 was kindly provided by Dr Joshua Rubin from Washington University in St Louis.

\section{Isolation and Analysis of RNA}

Total RNA was isolated from cell monolayers using the RNeasy kit (Qiagen Inc., Valencia, CA, USA) according to the manufacturer's directions. RNA was quantitated by absorbance at $260 \mathrm{~nm}$. For reverse transcription, $2 \mu \mathrm{g}$ of total RNA was reverse-transcribed using Super Script II RNase H reverse transcriptase (Invitrogen, Carlsbad, CA, USA) and random hexamer primers (Invitrogen, Carlsbad, CA, USA) at $25^{\circ} \mathrm{C}$ for $10 \mathrm{~min}$ and $42^{\circ} \mathrm{C}$ for $1 \mathrm{~h}$ for cDNA synthesis. In total, $2 \mu \mathrm{l}$ of the reverse transcription product was used as a template for PCR amplifica-
Table 1 PCR primers used for RT-PCR

\begin{tabular}{llc}
\hline Gene & Sequence & Product (bp) \\
\hline HIF-1 $\alpha$ & GTCGGACAGCCTCACCAAACAGAGC (s) & 487 \\
& GTTAACTTGATCCAAAGCTCTGAG (as) & \\
CXCR4 & CTGAGAAGCATGACGGACAA (s) & 274 \\
& CGCCAACATAGACCACCTTT (as) & \\
VEGF & CGAAGTGGTGAAGTTCATGGATG (s) & 535 (VEGF165) \\
& TTCTGTATC AGTCTTCCTGGT (as) & 403 (VEGF121) \\
$\beta$-Actin & GTACCACTGGCATCGTGATGGACT (s) & 600 \\
& ATCCACACGGAGTACTTGCGCTCA (as) & \\
\hline
\end{tabular}

tion. PCR was performed under standard conditions in a $50 \mu \mathrm{l}$ reaction mix containing $1 \times$ PCR buffer, $1 \mathrm{U}$ of Platinum Taq polymerase (Invitrogen, Carlsbad, CA, USA), $200 \mu \mathrm{M}$ dNTP mix, $1.5 \mathrm{mM} \mathrm{MgCl}_{2}$, $100 \mathrm{nM}$ of primers. Primers used are listed in Table 1 and were designed using MIT Primer3 software and as previously described. ${ }^{39}$ The PCR conditions consisted of $3 \mathrm{~min}$ of an initial denaturation step $\left(95^{\circ} \mathrm{C}\right)$ followed by 25 cycles of denaturation $\left(95^{\circ} \mathrm{C}\right.$, $30 \mathrm{~s})$, annealing $\left(55^{\circ} \mathrm{C}, 30 \mathrm{~s}\right)$, and extension $\left(72^{\circ} \mathrm{C}\right.$, $50 \mathrm{~s}$ ) followed by a final elongation step of $7 \mathrm{~min}$ at $72^{\circ} \mathrm{C}$ for HIF- $1 \alpha$ and $\beta$-actin. The PCR conditions for VEGF consisted of 30 cycles of denaturation $\left(95^{\circ} \mathrm{C}, 30 \mathrm{~s}\right)$, annealing $\left(60^{\circ} \mathrm{C}, 1 \mathrm{~min}\right)$, and extension $\left(72^{\circ} \mathrm{C}, 1 \mathrm{~min}\right)$. For CXCR4, after initial 35 cycles of denaturation $\left(95^{\circ} \mathrm{C}, 30 \mathrm{~s}\right)$, annealing $\left(55^{\circ} \mathrm{C}, 30 \mathrm{~s}\right)$ and extension $\left(72^{\circ} \mathrm{C}, 50 \mathrm{~s}\right)$ were used. PCR product $(20 \mu \mathrm{l})$ was analyzed on $3 \%$ agarose gels stained with ethidium bromide. Quantitation of bands was performed with the BioRad Fluor-S apparatus (BioRad, Hercules, CA, USA) with Quantity One (Version 4.2.1) software.

\section{HIF-1 $\alpha$ Transfection}

U87MG glioma cells were cultured for $24 \mathrm{~h}$ under normoxia $\left(20 \% \mathrm{O}_{2}\right)$ in six-well plates in DMEM/F12 medium with $10 \%$ FBS (Life Technologies, Inc., Gaithersburg, MD, USA) until $60-70 \%$ confluence was reached. Cells were transiently transfected using Lipofectamine Plus ${ }^{\mathrm{TM}}$ according to the manufacturer's protocol. The vector for pHIF- $1 \alpha \mathrm{DN}$, pCEP4, kindly provided by Dr Gregg Semenza from the Johns Hopkins University, contains a hygromycin-resistance gene (Invitrogen, Carlsbad, CA, USA). Cells transfected with the empty pCEP4 expression vector served as controls for all experiments. After transfection, cells were grown in selective medium (10\% FBS-DMEM containing $200 \mu \mathrm{g}$ of hygromycin/ $\mathrm{ml}$ ), and several clones of each were randomly selected and subsequently expanded in selective medium. Early passages of the transfected clones were frozen and stored in liquid nitrogen before being used for in vitro experiments. Screening for successful transfection was carried out by Western 
blotting analysis and immunofluorescence for nuclear HIF- $1 \alpha$ protein levels. Cells were kept in culture for a maximum of 4-5 additional passages in selective medium. All experiments were repeated three times.

\section{Lentivirus Production and Infection of Glioma Cells}

The shRNA directed against HIF- $1 \alpha$ was a kind gift of Dr Lawrence Gardner from New York University. shRNA sequence for HIF-1 $\alpha$ was (CCG GAG AGG TGG ATA TGT CTG GGC TCG AGC CCA GAC ATA TCC ACC TCT TTT TT) and the scramble sequence was (CCG GGG GTC TGT ATA GGT GGA GAC TCG AGT CTC CAC CTA TAC AGA CCC TTT TT). Recombinant lentiviruses were produced by cotransfecting human embryonic kidney (HEK) 293T cells with the lentivirus expression plasmid (pLKO.1 puro) and packaging plasmids $(\Delta 8.9$ and vsv-g) using Fugene as a transfection reagent. ${ }^{40}$ HEK 293T cells were cultured in Dulbecco's modified Eagle's medium (DMEM) supplemented with 10\% fetal bovine serum, $1 \%$ penicillin/streptomycin, in a $37^{\circ} \mathrm{C}$ incubator with $5 \% \mathrm{CO}_{2}$. Infectious lentiviruses were collected at 24,48 and $72 \mathrm{~h}$ after transfection. The collected supernatant was centrifuged to remove cell debris and filtered afterwards through a $0.45 \mu \mathrm{m}$ filtration unit. LN308 glioma cells were infected with the lentivirus producing shRNA directed against HIF-1 $\alpha$. Stable transfectants were selected in puromycin for 7 days.

\section{Western Blot Analysis}

Glioma cells $\left(2 \times 10^{6}\right)$ were seeded in $10 \mathrm{~cm}^{2}$ dishes in complete growth medium. After $48 \mathrm{~h}$, medium was changed to DMEM containing 1\% FBS and $50 \mathrm{mM}$ HEPES ( $\mathrm{pH} 7.4$ ), and exposed to $20 \% \mathrm{O}_{2}$ (standard $95 \%$ air $/ 5 \% \mathrm{CO}_{2}$ incubator) or $1 \% \mathrm{O}_{2}$ for 8, 16 and $24 \mathrm{~h}$. HBMECs $\left(2 \times 10^{6}\right.$ cells $)$ were seeded in complete growth medium. After $48 \mathrm{~h}$, medium was changed to serum-free medium (Cat \# 4Z0-500) containing $50 \mathrm{mM}$ HEPES. Cells were untreated or exposed to VEGF ( $50 \mathrm{ng} / \mathrm{ml}$ ) for 8, 16 and $24 \mathrm{~h}$ under $20 \% \mathrm{O}_{2}$ condition. Cells were lysed in RIPA buffer (150 mM NaCl, 1\% Nonidet P-40, 1\% deoxycholate, 0.1\% SDS, 10 mM Tris-HCl, $\mathrm{pH}$ 8.0, 1 mM EDTA, $\mathrm{pH}$ 8.0) supplemented with protease inhibitors (1 mM phenylmethylsulfonyl fluoride; PMSF $0.2 \mathrm{mM}$ sodium orthovanadate and $1 \mu \mathrm{g} / \mathrm{ml}$ aprotinin). Quantitation of protein was carried out with the BCA reagent (Pierce, Rockford, IL, USA). Equal amounts of protein $(30 \mu \mathrm{g})$ in the presence of $5 \% \beta$-mercaptoethanol (Sigma-Aldrich, Saint Louis, MO, USA) were electrophoresed on $7.5 \%$ SDS-PAGE gels and transferred to Immobilon-P membranes (Millipore, Bedford, MA, USA) by electroblotting at $4^{\circ} \mathrm{C}$ at $33 \mathrm{~V}$ overnight. Western blot analysis was performed as described $^{23}$ with the following antibodies: mouse anti-HIF-1 $\alpha$ monoclonal antibody used at 1:1000 (clone 54, BD Transduction Laboratories, San Jose, CA, USA), rabbit polyclonal anti-CXCR4 (IMG-537, IMGENEX, San Diego, CA, USA) used at 1:500 and mouse anti-actin monoclonal antibody used at 1:50 000 (clone C4, Chemicon International, Inc., Temecula, CA, USA). Sheep anti-mouse IgG (Amersham Life Pharmacia Biotech, Piscataway, NJ, USA) and horseradish peroxidase-conjugated secondary antibodies were used at 1:2000. Immunodetection was carried out either with the Supersignal West Femto (HIF-1 $\alpha$ ) or Pico (actin). Maximum Sensitivity Substrate ECL detection system (Pierce Biotechnology Inc., Rockford, IL, USA) was followed by visualization and densitometry using NIH Image software.

\section{Immunofluorescent Microscopy}

U87MG cells $\left(3 \times 10^{4}\right)$ were seeded onto poly-Dlysine-coated glass coverslips and incubated overnight. Cells were grown under normoxia $\left(20 \% \mathrm{O}_{2}\right)$ or hypoxia $\left(\begin{array}{ll}1 \% & \mathrm{O}_{2}\end{array}\right)$ for $24 \mathrm{~h}$ and processed for immunofluorescence. For immunofluorescence, cells were fixed in $4 \%$ paraformaldehyde in PBS for $15 \mathrm{~min}$, then washed for $5 \mathrm{~min}$ in PBS, permeabilized for $10 \mathrm{~min}$ in $0.5 \%$ Igepal (Sigma-Aldrich, Saint Louis, MO, USA), followed by a final wash of PBS for $5 \mathrm{~min}$; all steps were performed at room temperature. Nonspecific binding was blocked by incubation in blocking buffer containing $2 \%$ bovine serum albumin (BSA) in PBS for $30 \mathrm{~min}$ at room temperature. Cells were incubated overnight at $4^{\circ} \mathrm{C}$ with primary mouse monoclonal anti-HIF-1 $\alpha$ antibody (BD Transduction Labs, San Jose, CA, USA; \#610959) diluted 1:200 in blocking buffer. Cells were washed in blocking buffer three times for $5 \mathrm{~min}$ each before incubation with secondary donkey antimouse FITC-conjugated antibody (Jackson Immunoresearch, West Grove, PA, USA) diluted 1:300 in blocking buffer for $2 \mathrm{~h}$ at room temperature in the dark. For CXCR4 immunofluorescence, primary polyclonal anti-CXCR4 goat IgG (Santa-Cruz Biotechnology; clone G-19) was used in blocking buffer at 1:200. The secondary antibody was a donkey antigoat Texas Red conjugated antibody (Jackson Immunoresearch) at 1:300. After three washes in PBS, cells were counterstained with propidium iodide (PI, $20 \mu \mathrm{g} / \mathrm{ml}$ ) or DAPI ( $100 \mathrm{ng} / \mathrm{ml}$ ) for $20 \mathrm{~min}$ at room temperature. After washing three times in PBS, coverslips were mounted onto Fisher ColorFrost glass slides using ProLong antifade kit (Molecular Probes, Eugene, OR, USA). Images were captured using a Nikon Fluorescence microscope and adjusted using Adobe Photoshop 7.0 software.

\section{Migration Assay}

Millipore Millicell inserts (Millipore, Carrigtwohill, Co. Cork, Ireland) with 8- $\mu$ m pore size polystyrene filter inserts for 24-well plates were used according 
to the manufacturer's instructions and as described. ${ }^{41}$ Briefly, cells $\left(5 \times 10^{4}\right)$ in $400 \mu$ l of DMEM medium with $10 \%$ FBS were seeded onto the upper compartment of each chamber and placed into wells containing $600 \mu \mathrm{l}$ of complete medium. Cells were allowed to adhere for $1.5 \mathrm{~h}$, and then the medium in the upper chamber was replaced with complete medium with or without different concentrations of AMD3100. The migration chambers were incubated for $24 \mathrm{~h}$ in normoxic $\left(20 \% \mathrm{O}_{2}\right)$ or hypoxic $\left(1 \% \mathrm{O}_{2}\right)$ conditions at $37^{\circ} \mathrm{C}$. Following incubation, the inserts were fixed in absolute methanol for $2 \mathrm{~min}$ at room temperature and stained with $1 \%$ toluidine blue in $1 \%$ borax for $3 \mathrm{~min}$. The cells on the upper surface of the insert were mechanically removed with a cotton-tipped swab. Quantitation of migrating cells on the lower surface of each filter was done by counting six random fields under a light microscope (final magnification $\times 100$ ). Each assay was performed in duplicate. The data from three independent experiments was pooled for statistical analysis. Images were quantified for number of cells $/ 10 \times$ field by using NIH Image software (version 1.62).

\section{Statistical Analysis}

Experiments were performed at least two or three times and determinations were performed in replicates. Results are expressed as mean \pm standard deviation. All analyses for the conditions being compared were performed using a two-sided Student's $t$-test for significance $(P<0.05)$. All analyses used Stat View software (SAS Inst., Cary, NC, USA).

\section{Results}

\section{HIF-1 $\alpha$ and CXCR4 Expression in GBMs}

We performed immunohistochemistry on paraffinembedded sections to determine the expression levels and localization of HIF- $1 \alpha$ and CXCR4 in normal brain compared with 18 GBMs. The results are summarized in Table 2. All 18 GBM specimens were highly vascular. They showed moderate-tomarked cellular pleomorphism, hyperchromatic nuclei and displayed frequent mitotic figures. Necrosis was seen in all cases and was either focal (16 cases) or extensive (two cases). Vascularity was heterogeneous not only from tumor to tumor but also within individual tumors. Glomeruloid vascular complexes, representing the end result of an exuberant vascular proliferation with coiled masses of capillaries, were observed in 17 cases. HIF-1 $\alpha$ immunoreactivity was present in the tumor cells of all GBMs $(n=18)$ (see Table 2). The staining was especially intense in pseudopalisading tumor cells around areas of necrosis as previously described (Figure 1a and b). HIF-1 $\alpha$ was detected in tumor cells adjacent to activated vascular channels, especially
Table 2 HIF- $1 \alpha$ and CXCR4 expression in GBMs

\begin{tabular}{|c|c|c|c|c|}
\hline \multirow[t]{2}{*}{ Bank case number } & \multicolumn{2}{|c|}{$H I F-1 \alpha$} & \multicolumn{2}{|c|}{ CXCR4 } \\
\hline & $V$ & $T$ & $V$ & $T$ \\
\hline 1 & - & + & - & + \\
\hline 2 & - & + & + & - \\
\hline 3 & - & + & + & + \\
\hline 4 & - & ++++ & + & ++++ \\
\hline 5 & - & +++ & - & +++ \\
\hline 6 & - & +++ & + & +++ \\
\hline 7 & - & + & + & - \\
\hline 8 & - & ++ & + & ++ \\
\hline 9 & - & ++ & + & +++ \\
\hline 10 & - & +++ & + & +++ \\
\hline 11 & - & +++ & ++ & ++++ \\
\hline 12 & - & + & + & + \\
\hline 13 & - & ++++ & + & +++ \\
\hline 14 & - & +++ & ++ & +++ \\
\hline 15 & - & ++ & ++ & +++ \\
\hline 16 & - & +++ & + & +++ \\
\hline 17 & - & + & ++ & + \\
\hline 18 & - & ++++ & +++ & ++++ \\
\hline
\end{tabular}

HIF- $1 \alpha$ and CXCR4 immunohistochemical quantitation and localization in GBMs. V, vascular; T, tumor. Scoring: -, no staining; +, staining of less than $1 \%$ of cells; ++, staining of $1-10 \%$ of cells; +++ , staining of less than $10-50 \%$ of cells; ++++, staining of greater than $50 \%$ of cells. In normal brain tissue, HIF- $1 \alpha$ and CXCR4 overall staining was negative.

near vessels with hyperplastic changes. In some GBMs, multiple clusters of immunostained tumor nuclei were detected. In many of these cases, deeper cuts into the tissue block revealed that the immunostained tumor cells were adjacent to necrotic zones. In every case, staining for HIF- $1 \alpha$ was primarily observed in tumor cells and not in vascular cells. Tumor cells in three cases were $4+$ staining, six cases had $3+$, three had $2+$ and six had $1+$.

CXCR4 expression was noted in 16 out of 18 GBM cases. The pattern of CXCR4 immunostaining was similar in its distribution as seen for HIF-1 $\alpha$ (Table 2). CXCR4 was highly expressed in areas of tumor adjacent to necrosis, that is, in pseudopalisading cells (Figure 1c and d), suggesting that the pattern of CXCR4 expression in GBMs is, at least in part, modulated by tumor oxygenation. In three cases, CXCR4 was localized to the cytoplasm only, whereas in six cases both cytoplasmic and nuclear localization was detected and in seven cases, the staining was nuclear only. In tumor cells, three cases were scored as $4+$, eight cases were scored as $3+$, one was $2+$, and four were $1+$. CXCR4 immunoreactivity was negative in two tumors. CXCR4 immunoreactivity highlighted cellular contours in a pattern consistent with membranous staining. Interestingly, CXCR4 was also detected in vascular cells (Figure 1, Table 2). In four cases, CXCR4 was localized to the cytoplasm only, whereas in three cases both cytoplasmic and nuclear localization was detected and in nine cases was nuclear only. One case was scored 

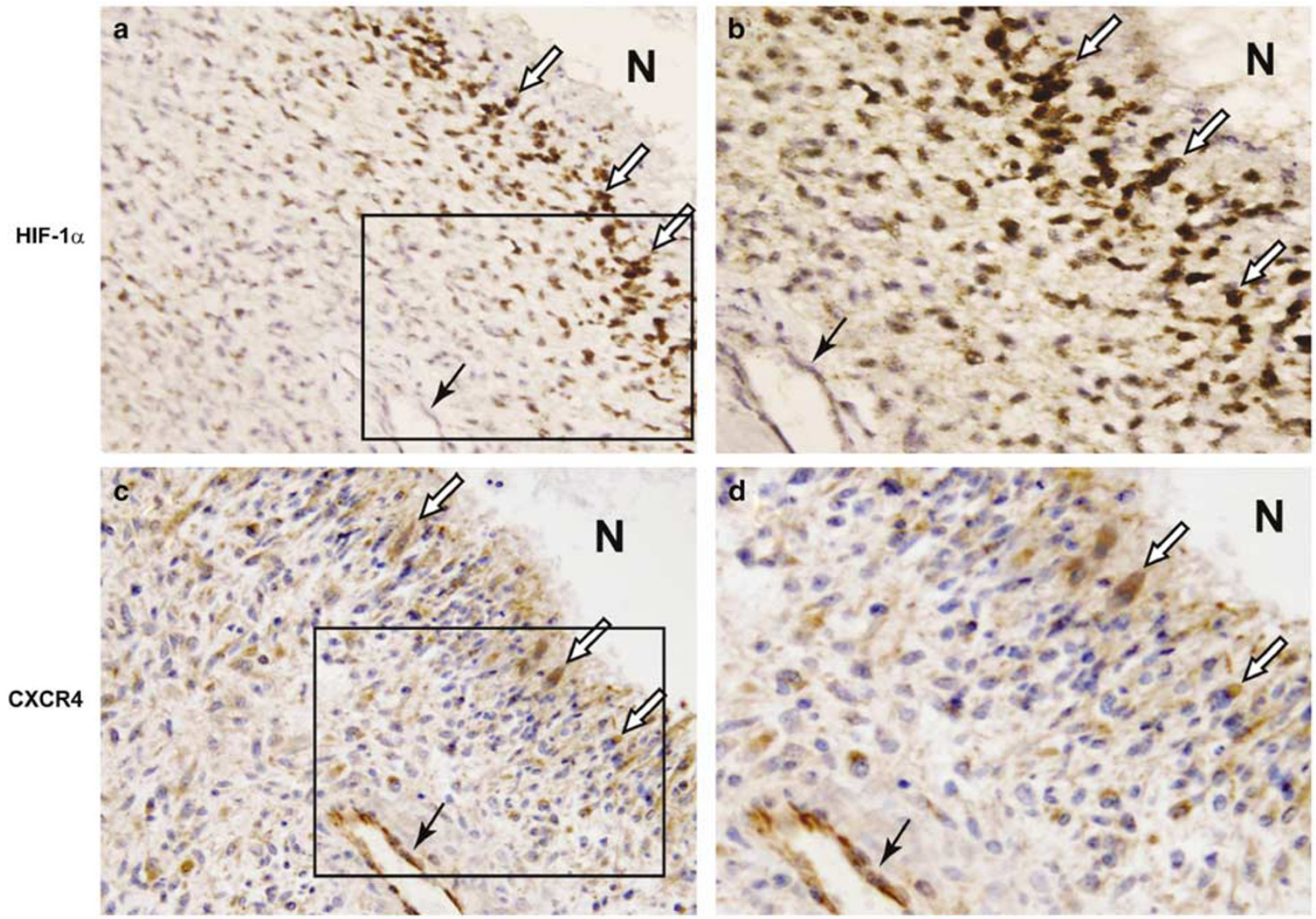

Figure $1 \mathrm{HIF}-1 \alpha$ and CXCR4 expression in GBMs. (a, b) HIF-1 $\alpha$ immunohistochemistry reveals intense staining in pseudopalisading tumor cells (white arrows) around areas of necrosis (N), whereas hyperplastic vessels are unstained (black arrow). (b) Area outlined by the box in (a). (c, d) CXCR4 immunohistochemistry reveals intense staining in pseudopalisading tumor cells (white arrows) and in vascular cells (black arrow). (d) Area outlined by the box in (c). (a and $\mathbf{c})$; (b and $\mathbf{d})$ represent adjacent sections (a and $\mathbf{c}, \times 100, \mathbf{b}$ and $\mathbf{d}$, $\times 400)$.

as $3+$ staining, four were $2+$, and eleven were $1+$. No staining was detected in two cases.

In 11 GBMs where brain tissue was observed more distant from the tumor, no detectable staining for HIF-1 or CXCR4 was observed as previously described. ${ }^{15,31}$ Thus, reactivity for CXCR4 was colocalized to regions of necrosis and angiogenic vessels, ${ }^{31}$ whereas HIF-1 was only observed in hypoxic tumor cells, for example pseudopalisading cells. ${ }^{15}$ Finally, for both HIF- $1 \alpha$ and CXCR4, in all cases, no staining was observed with isotype-matched murine mAb controls or in the absence of primary antibody.

\section{Effects of Hypoxia on CXCR4 Expression in Glioma Cells}

As levels of CXCR4 seemed to correlate with HIF-1 $\alpha$ expression in glioma tumor samples, we wanted to investigate the effect of hypoxia on CXCR4 expression in vitro. Therefore, cultures of LN308 and U87MG glioma cells were exposed to normoxia $\left(20 \% \mathrm{O}_{2}\right)$ or hypoxia $\left(1 \% \mathrm{O}_{2}\right)$ for 8,16 and $24 \mathrm{~h}$ and the expression of HIF-1 $\alpha$, VEGF and CXCR4 mRNA was analyzed by RT-PCR. Hypoxia upregulated VEGF and CXCR4 mRNAs but not HIF- $1 \alpha$ mRNA
(Figure 2a). Our results are consistent with other reports showing that cells cultured under hypoxic conditions $\left(\mathrm{O}_{2} 1 \%\right)$ do not increase HIF- $1 \alpha$ mRNA. ${ }^{4,8}$ The VEGF mRNA for both the 121 and 165 isoforms was increased by $8 \mathrm{~h}$ and remained elevated over the $24 \mathrm{~h}$ treatment interval. CXCR4 mRNA was increased as early as $8 \mathrm{~h}$ and maintained through $24 \mathrm{~h}$.

To determine if the increase in mRNA for CXCR4 was translated into an upregulation of the protein, Western blots were performed. LN308 and U87MG glioma cells showed different levels of constitutive CXCR4 expression as previously reported..$^{33}$ Moreover, LN308 and U87MG glioma cells expressed higher levels of both HIF- $1 \alpha$ and CXCR4 proteins under hypoxic conditions (Figure $2 \mathrm{~b}$ and $\mathrm{c}$ ). This was seen as early as $8 \mathrm{~h}$ and was maintained through the $24 \mathrm{~h}$ interval. Quantitation of protein bands detected by Western blot showed that HIF-1 $\alpha$ protein levels were significantly increased at all time points for both LN308 and U87MG glioma cells $(P<0.05)$. CXCR4 protein levels were increased significantly at all time points for LN308 cells $(P<0.05)$, whereas in U87MG glioma cells CXCR4 levels were significantly increased only at $24 \mathrm{~h}(P<0.05)$. These data provide evidence that CXCR4 mRNA and protein expression are upregulated by hypoxia. 


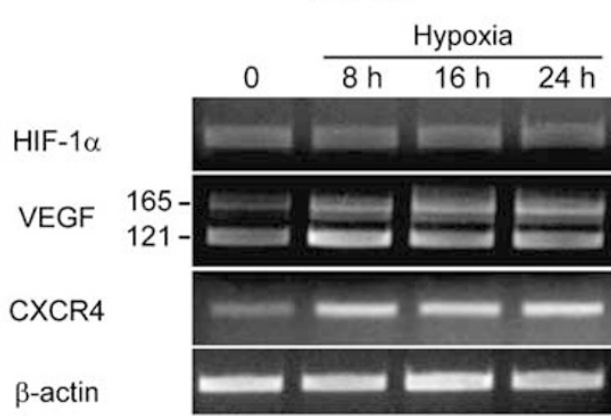

b

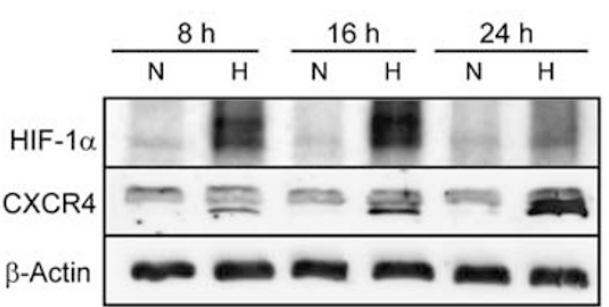

C
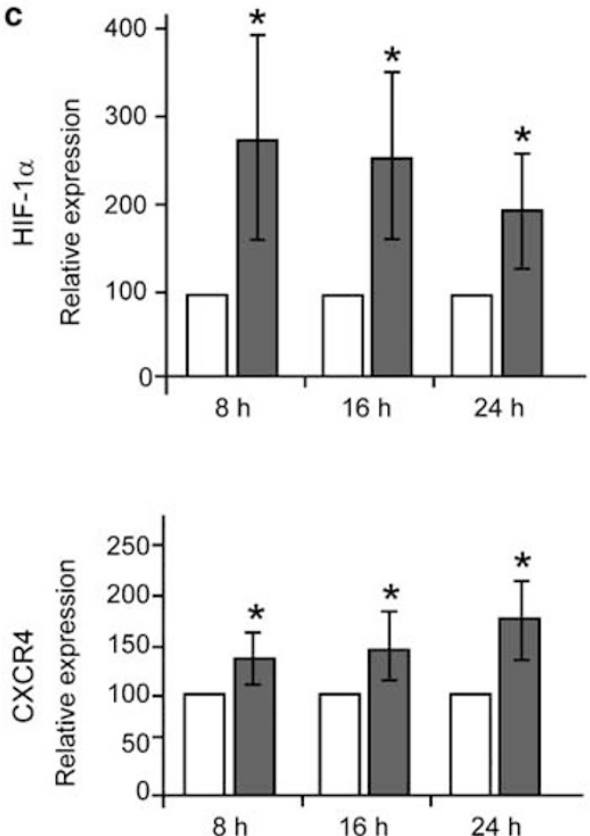

U87MG

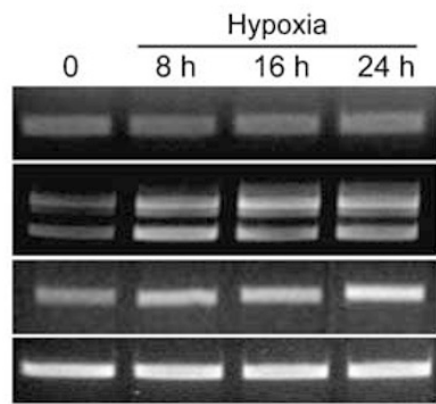

U87MG
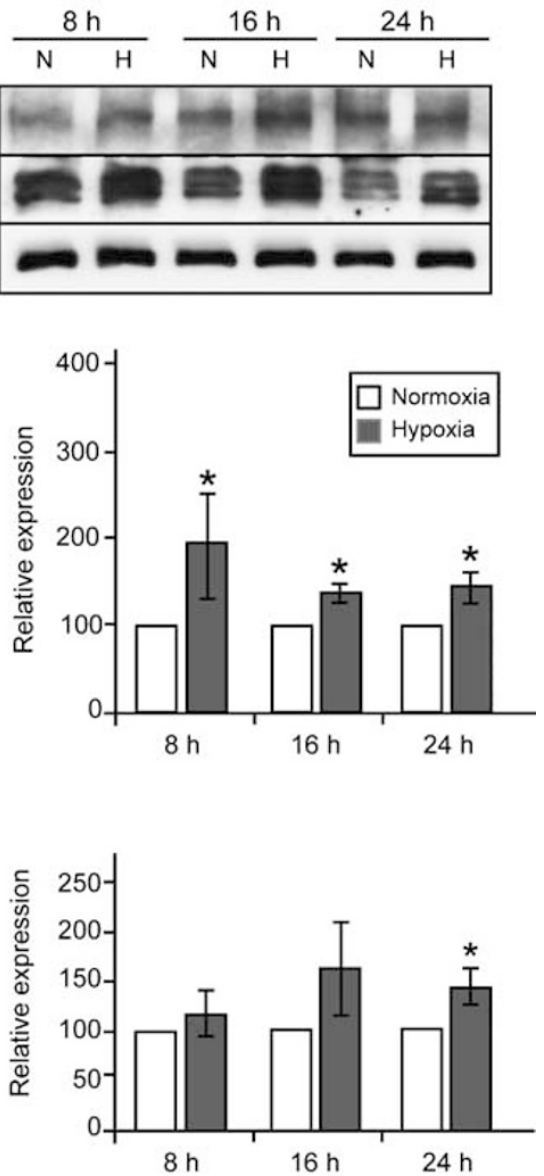

Figure 2 Effect of hypoxia on HIF-1 $\alpha$ and CXCR4 expression in glioma cells. (a) Gene expression levels determined by RT-PCR. Cultures of LN308 and U87MG glioma cells were grown under normoxia or hypoxia for the indicated time intervals. Total RNA was extracted and the expression of HIF-1 $\alpha$, VEGF and CXCR4 mRNA was analyzed by RT-PCR. Both VEGF and CXCR4 mRNA are upregulated by hypoxia. $\beta$-Actin was used as an internal control. Representative data from one of three independent experiments is shown. (b) Protein expression levels determined by Western blot. Cultures of LN308 and U87MG glioma cells were grown under normoxia (N) or hypoxia (H) for the indicated time intervals. HIF- $1 \alpha$ and CXCR4 protein levels are increased by hypoxia. Representative Western blot results are shown from one of three independent experiments. $\beta$-Actin was used as the loading control. (c) Bar graphs represent data pooled from three independent experiments for statistical analysis comparing levels of HIF-1 $\alpha$ and CXCR4 expression in different groups. ${ }^{*} P<0.05$, significant difference from respective control.

\section{Effects of HIF-1 $\alpha$ on CXCR4 Expression}

To further link expression of HIF- $1 \alpha$ to that of CXCR4, we transfected U87MG glioma cells with the HIF-1 $\alpha$ gene. Western blot for HIF- $1 \alpha$ and CXCR4 in cells under normoxic conditions showed strong upregulation of HIF- $1 \alpha$ and CXCR4 in transfected U87MG cells (U87MG/HIF-1 $\alpha$ ) but not in parental cells or in cells transfected with empty vector (Figure 3a). Nontransfected parental cells under hypoxic conditions also showed upregulation of HIF-1 $\alpha$ and CXCR4. Immunofluorescence studies 
showed upregulation of HIF-1 $\alpha$ and CXCR4 staining in normoxic-transfected U87MG glioma cells (U87MG/HIF-1 $\alpha$ ) or in nontransfected parental cells exposed to hypoxia (Figure 3b).

To further explore the role of HIF- $1 \alpha$ in CXCR4 induction, we used a lentivirus-mediated shRNA

$$
\text { a }
$$
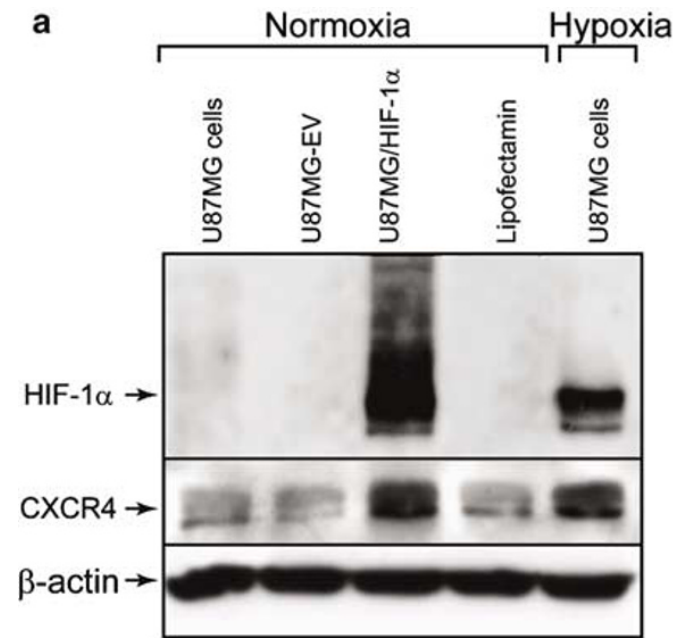

\section{b}

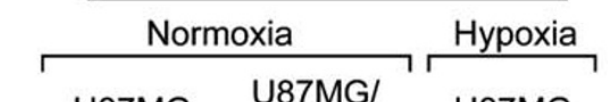

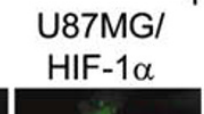

U87MG
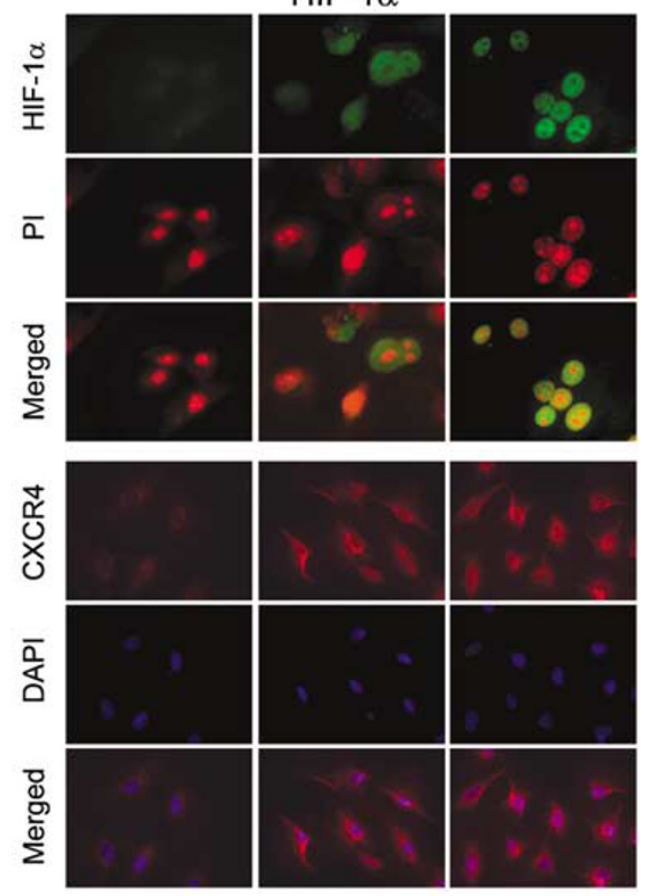

C

LN308

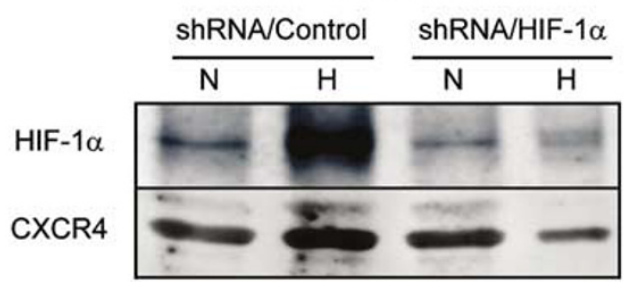

expression vector directed against HIF-1 $\alpha$. Using this approach, we effectively inhibited HIF-1 $\alpha$ expression concomitant with CXCR4 upregulation under hypoxic conditions. We selected LN308 glioma cell line based on its robust hypoxiamediated upregulation of HIF-1 $\alpha$ (Figure 2b). When exposed to hypoxic conditions, LN308 glioma cells infected with lentivirus containing scramble sequences showed an upregulation of $\mathrm{HIF}-1 \alpha$, which paralleled an overexpression of CXCR4 (Figure 3c). By contrast, in cells infected with the shRNA directed against HIF- $1 \alpha$, HIF- $1 \alpha$ and the CXCR4 upregulation under hypoxic conditions was blocked.

\section{Effects of VEGF on CXCR4 Expression in HBMECs}

As we observed strong CXCR4 immunoreactivity in hyperplastic vessels but not in vessels of the normal brain, we wanted to identify chemokines that might be potential inducers of CXCR4 expression in HBMECs. We began by exposing HBMECs to $50 \mathrm{ng} /$ $\mathrm{ml}$ VEGF for the indicated time intervals (Figure 4). The expression of CXCR4 mRNA was then analyzed by RT-PCR. HBMECs constitutively expressed CXCR4 mRNA, which increased approximately three-fold after treatment with VEGF by $8 \mathrm{~h}$ with further increases at 16 and $24 \mathrm{~h}$ of about 10-fold (Figure 4a). CXCR4 protein levels of expression in HBMECs was significantly increased after stimulation with VEGF. Quantitation of protein bands detected by Western blot showed a significant increase at $24 \mathrm{~h}(P<0.05)$ (Figure $4 \mathrm{~b}$ and $\mathrm{c})$.

\section{Effect of Hypoxia and CXCR4 Inhibition on Glioma Cell Migration}

Next, we determined the effect of hypoxia on U87MG and LN308 cellular migration. Results from three independent experiments are shown in Figure

\footnotetext{
Figure 3 Effects of HIF- $1 \alpha$ on CXCR4 expression. (a) Detection of HIF-1 $\alpha$ and CXCR4 in transfected U87MG glioma cells by Western blot. Cells transfected with HIF- $1 \alpha$ show upregulation of HIF- $1 \alpha$ and CXCR4 under normoxic conditions compared with cells transfected with the empty vector and normoxic parental cells. Nontrasfected parental cells do show HIF-1 $\alpha$ and CXCR4 upregulation when grown in hypoxic conditions. The data in the figure are representative of three independent experiments. (b) Detection of HIF-1 $\alpha$ and CXCR4 in transfected U87MG cells by immunofluorescence. U87MG glioma cells transfected with HIF$1 \alpha$ or exposed to hypoxia show upregulation of both HIF-1 $\alpha$ (nuclear green fluorescence) and CXCR4 (membranous red fluorescence). Cells were counterstained with propidium iodide (PI, red fluorescence) or with DAPI (blue fluorescence) to visualize the nuclei. $\times 40$. (c) Detection of HIF- $1 \alpha$ and CXCR4 in LN308 glioma by Western blot. Cultures of LN308 glioma cells were grown under normoxia $(\mathrm{N})$ or hypoxia $(\mathrm{H})$. Infection with the lentivirus-mediated shRNA expression vector directed against HIF-1 $\alpha$ effectively blocks hypoxia-mediated upregulation of HIF-1 and CXCR4 compared with cells infected with the scramble sequence.
} 
a
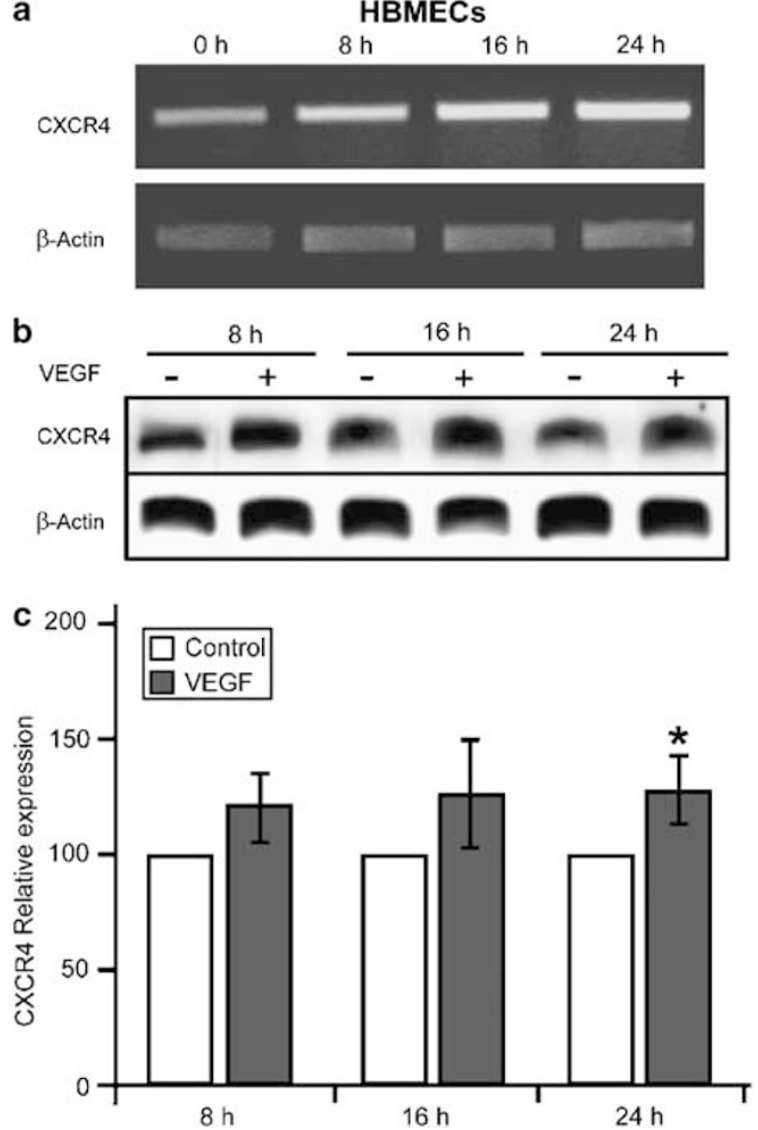

Figure 4 Effect of VEGF on CXCR4 expression in HBMECs. (a) Gene expression levels determined by RT-PCR. VEGF treatment increases CXCR4 mRNA over $24 \mathrm{~h}$ period. $\beta$-Actin expression was included as an internal control. Data from one of three independent experiments is shown. (b) Protein expression levels determined by Western blot. VEGF treatment significantly increases CXCR4 protein levels at $24 \mathrm{~h}(P<0.05)$. The expression for $\beta$-actin was used as the loading control. Representative Western blot results are shown from one of three independent experiments. (c) Bar graphs represent data pooled from three independent experiments for statistical analysis comparing levels of CXCR4 expression in different groups. ${ }^{*} P<0.05$, significant difference from respective control.

5. Cells were cultured under normoxic $\left(20 \% \mathrm{O}_{2}\right)$ or hypoxic $\left(1 \% \mathrm{O}_{2}\right)$ conditions in the presence or absence of different concentrations of AMD3100. After incubation for $24 \mathrm{~h}$, the number of cells that migrated through the membrane was quantitated. In hypoxic conditions, migration of both U87MG and LN308 cells was significantly increased as compared to control normoxic cultures $(P<0.001)$. The CXCR4 inhibitor AMD3100 significantly inhibited this hypoxia-stimulated migration of U87MG and LN308 glioma cells $(P<0.001)$.

\section{Discussion}

Our results demonstrate that the pattern of CXCR4 expression observed in GBMs only partly overlaps with that of HIF-1 $\alpha$. Because CXCR4 was also expressed in nonhypoxic vascular cells that did not express HIF-1 $\alpha$, we hypothesized that CXCR4 might be regulated by VEGF released by pseudopalisading cells. Thus, we also tested the effect of VEGF on the expression of CXCR4 in HBMECs. We suggest that hypoxia in gliomas provides for at least two interconnected pathways for CXCR4 upregulation (Figure 6). One route involves HIF-1 $\alpha$ in pseudopalisading glioma cells, and the other implicates VEGF in CXCR4 upregulation in angiogenic vessels.

Others have shown that hypoxia increases CXCR4 expression through HIF-1 activation via an HRE in the $5^{\prime}$ region of the CXCR4 gene. ${ }^{22}$ HIF-1 enhances the expression and function of CXCR4 in normal cells (eg monocytes, macrophages, endothelial cells) ${ }^{42}$ and also in malignant cells (eg renal cell carcinomas and hemangioblastomas). ${ }^{22,23}$ Under regular oxygen tension, pVHL, the product of the von Hippel-Lindau tumor suppressor gene (VHL), induces degradation of HIF- $1 \alpha$. However, during hypoxia, or in cases of renal cell carcinoma or hemangioblastomas that harbor mutations in the $V H L$ gene, HIF- $1 \alpha$ accumulates, which in turn leads to CXCR4 upregulation. ${ }^{23}$ We demonstrate that there is a coexpression of HIF- $1 \alpha$ and CXCR4 in the hypoxic pseudopalisading cells of GBMs (Figures 1 and 6). In addition, we went on to show that glioma cells cultured in hypoxic conditions or those having increased HIF- $1 \alpha$ expression had a concomitant increase in CXCR4 message and protein levels. On the other hand, infection with a lentivirus-mediated shRNA expression vector directed against HIF-1 $\alpha$ prevented both HIF- $1 \alpha$ and CXCR4 upregulation. Thus, using this approach, we effectively inhibited HIF- $1 \alpha$ expression concomitant with CXCR4 upregulation under hypoxic conditions. Moreover, AMD3100, a CXCR4 inhibitor, was able to decrease the hypoxia-stimulated glioma cell migration. Some have suggested that the expression of hypoxiainducible genes implicated in migration would allow the cells to migrate away from the hypoxic environment. Specifically, CXCR4 might be needed to promote motility of tumor cells in a hypoxic environment allowing the tumor cells to migrate away from areas of low oxygen. ${ }^{43}$ Therefore, CXCR4 expression in glioma cells can be controlled by hypoxia and the levels of HIF- $1 \alpha$, and is associated with increased glioma cell migration.

Next to hypoxia and necrosis, a hallmark of GBMs is their high degree of vascularization, which has been linked to the overexpression of VEGF. ${ }^{1}$ Resting endothelial cells have low levels of CXCR4 that increase in response to VEGF stimulation. ${ }^{44-47}$ Experimental data suggest that angiogenesis mediated by CXCR4 is regulated at the receptor level by VEGF. ${ }^{42}$ We suggest it is possible that VEGF released by hypoxic pseudopalisading cells of GBMs can upregulate CXCR4 in endothelial cells. Other growth factors with angiogenic activities, for exam- 

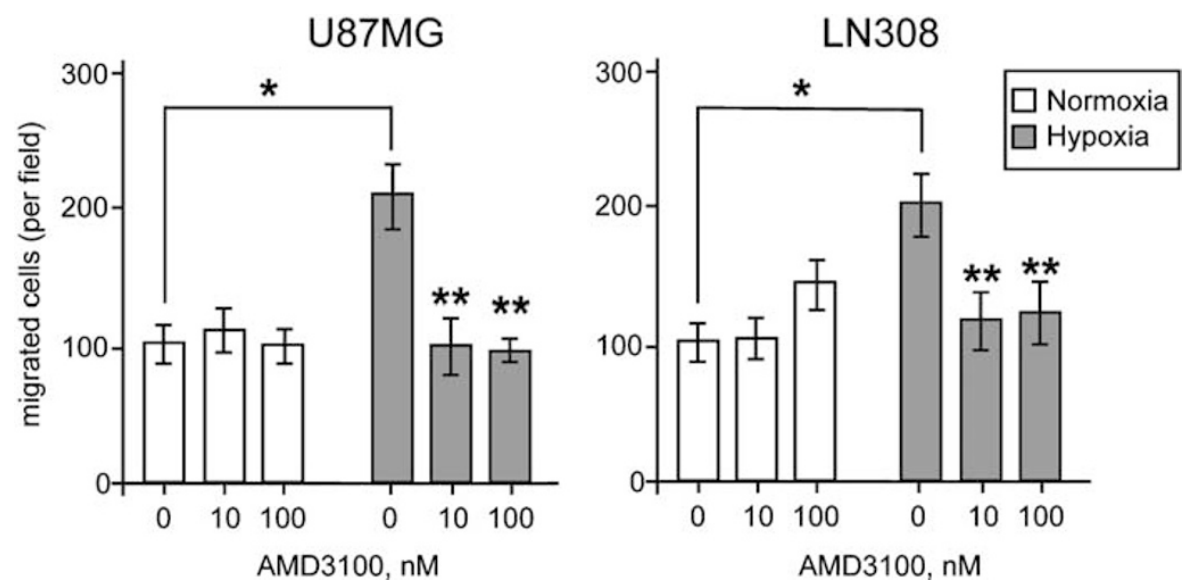

Figure 5 Effects of hypoxia and CXCR4 inhibition on the migration of glioma cells. U87MG and LN308 cells were tested under normoxia $\left(20 \% \mathrm{O}_{2}\right)$ or hypoxia $\left(1 \% \mathrm{O}_{2}\right)$ in the presence or absence of different concentrations of AMD3100. After incubation for $24 \mathrm{~h}$, the number of cells that migrated through the membrane was quantitated. Hypoxia treatment significantly increases the migration of U87MG and LN308 cells compared to control normoxic cultures $\left({ }^{*} P<0.001\right)$. Addition of AMD3100 significantly inhibits migration of U87MG and LN308 glioma cells under hypoxic conditions $\left({ }^{*} P<0.001\right)$. Bar graphs represent data pooled from three independent experiments for statistical analysis.

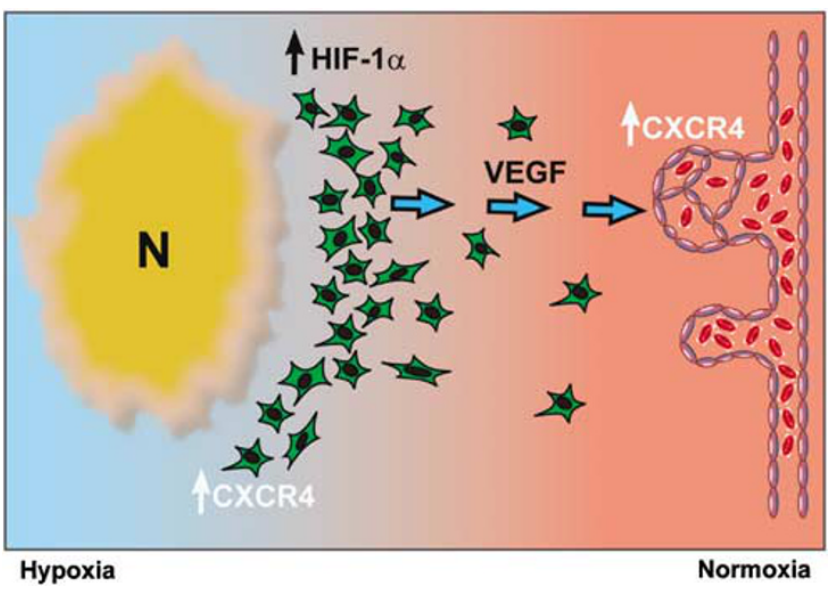

Figure 6 Molecular pathways leading to CXCR4 upregulation in glioblastoma. This schema diagrams two potential molecular pathways that may play a role in the upregulation of CXCR4 in GBMs, that is hypoxia and VEGF. Our immunohistochemical data in clinical specimens show that CXCR4 is expressed in angiogenic vessels and in pseudopalisading glioma cells around areas of necrosis. Our data suggest that in vivo hypoxic pseudopalisading glioma cells overexpress HIF- $1 \alpha$ that in turn may lead to CXCR 4 expression in these cells. Our findings in vitro also indicate that VEGF released by pseudopalisading cells could be, at least in part, responsible for the overexpression of CXCR4 in angiogenic vessels.

ple hepatocyte growth factor, known to be expressed in GBMs, ${ }^{48}$ have already been shown to enhance CXCR4 expression. ${ }^{49}$ These may also contribute to the expression of CXCR4 in the angiogenic component of GBMs. Indeed, we have demonstrated that, not only is CXCR4 expressed in angiogenic blood vessels adjacent to necrotic/hypoxic areas of GBMs but also HBMECs exposed to VEGF showed increased CXCR4 expression. VEGF has also been shown to upregulate CXCR4 expression on glioma cells. ${ }^{35}$

Others have also provided experimental evidence in support of a role for CXCR4 in angiogenesis: (i) mice lacking CXCR4 have defective vascular development, ${ }^{50}$ (ii) in vivo, blockade of CXCR4 in several murine tumor models results in inhibition of tumor neovascularization and growth ${ }^{51}$ and (iii) in addition, endothelial cells and their progenitors express CXCR4. ${ }^{52}$ Moreover, several biological observations implicate SDF-1, the specific ligand for CXCR4, in angiogenesis. SDF-1 acts as a chemoattractant for endothelial cells and their progenitors, induces endothelial cell proliferation in vitro, enhances VEGF-induced proliferation of endothelial cells, and induces microvessel formation and capillary sprouting in vivo. ${ }^{44,53,54}$ In addition, an angiogenic role of SDF-1 has been shown at sites of inflammation, ${ }^{53}$ wound repair ${ }^{55}$ and in gliomas. ${ }^{31}$ It has been proposed that the chemotactic influence of SDF$1 \alpha^{4,56}$ combined with the proliferative effects of VEGF may represent a powerful angiogenic signal. Thus, SDF-1/CXCR4 and VEGF/VEGFR pathways may collaborate to induce angiogenesis in GBMs. Future experimental studies are needed to further clarify this possible symbiotic molecular system.

In summary, we have demonstrated that CXCR4 levels are elevated in tumor and vascular cells of GBMs. We propose that in hypoxic pseudopalisading cells around areas of necrosis that overexpress HIF-1 $\alpha$, CXCR4 expression is primarily under the control of HIF-1, whereas VEGF released by the pseudopalisading cells is, at least in part, responsible for CXCR4 upregulation in endothelial cells. Because hypoxia is known as a potent stimulus for VEGF, we believe these molecular events are linked by hypoxia causing CXCR4 upregulation in GBMs (Figure 6). Taken together, our results suggest that 
CXCR4 may be a potentially useful therapeutic target and blocking its expression could represent a novel and efficient strategy to treat gliomas by interfering with the function of both glioma and endothelial cells.

\section{Acknowledgement}

We thank Luis Chiriboga for technical assistance. This work was supported by the National Institutes of Health grant R01 CA100426 (DZ).

\section{References}

1 Fischer I, Gagner JP, Law M, et al. Angiogenesis in gliomas: biology and molecular pathophysiology. Brain Pathol 2005;15:297-310.

2 Brown JM, Giaccia AJ. The unique physiology of solid tumors: opportunities (and problems) for cancer therapy. Cancer Res 1998;58:1408-1416.

3 Guillemin K, Krasnow MA. The hypoxic response: Huffing and HIFing. Cell 1997;89:9-12.

4 Semenza GL. Regulation of mammalian $\mathrm{O}_{2}$ homeostasis by hypoxia-inducible factor 1. Annu Rev Cell Dev Biol 1999;15:551-578.

5 Ferrara N. Vascular endothelial growth factor: basic science and clinical progress. Endocr Rev 2004;25: 581-611.

6 Carmeliet P, Dor Y, Herbert JM, et al. Role of HIF-1 $\alpha$ in hypoxia-mediated apoptosis, cell proliferation and tumour angiogenesis. Nature 1998;394:485-490.

7 Forsythe JA, Jiang BH, Iyer NV, et al. Activation of vascular endothelial growth factor gene transcription by hypoxia-inducible factor 1. Mol Cell Biol 1996;6: 4604-4613.

8 Semenza GL. Targeting HIF-1 for cancer therapy. Nat Rev Cancer 2003;3:721-732.

9 Giaccia A, Siim BG, Johnson RS. HIF-1 as a target for drug development. Nat Rev Drug Discov 2003;2: 803-811.

10 Powis G, Kirkpatrick L. Hypoxia inducible factor- $1 \alpha$ as a cancer drug target. Mol Cancer Ther 2004;3:647-654.

11 Brown JM, Wilson WR. Exploiting tumour hypoxia in cancer treatment. Nat Rev Cancer 2004;4:437-447.

12 Rapisarda A, Shoemaker RH, Melillo G. Targeting topoisomerase I to inhibit hypoxia inducbile factor 1. Cell Cycle 2004;3:172-175.

13 Yeo EJ, Chun YS, Park JW. New anticancer strategies targeting HIF-1. Biochem Pharmacol 2004;68: 1061-1069.

14 Weiss RH, Lin PY. Kidney cancer: identification of novel targets for therapy. Kidney Int 2006;69:224-232.

15 Zagzag D, Zhong H, Scalzitti JM, et al. Expression of hypoxia-inducible factor $1 \alpha$ in brain tumors: association with angiogenesis, invasion, and progression. Cancer 2000;88:2606-2618.

16 Birner P, Gatterbauer B, Oberhuber G, et al. Expression of hypoxia-inducible factor- $1 \alpha$ in oligodendrogliomas: its impact on prognosis and on neoangiogenesis. Cancer 2001;92:165-171.

17 Zhong H, De Marzo AM, Laughner E, et al. Overexpression of hypoxia-inducible factor $1 \alpha$ in common human cancers and their metastases. Cancer Res 1999;59:5830-5835.
18 Nakanishi K, Hiroi S, Tominaga S, et al. Expression of hypoxia-inducible factor- $1 \alpha$ protein predicts survival in patients with transitional cell carcinoma of the upper urinary tract. Clin Can Res 2005;11:25832590.

19 Vleugel MM, Greijer AE, Shvarts A, et al. Differential prognostic impact of hypoxia induced and diffuse HIF$1 \alpha$ expression in invasive breast cancer. J Clin Pathol 2005;58:172-177.

20 Shweiki D, Itin A, Soffer D, et al. Vascular endothelial growth factor induced by hypoxia may mediate hypoxia-initiated angiogenesis. Nature 1992;359: 843-845.

21 Damert A, Machein M, Breier G, et al. Up-regulation of vascular endothelial growth factor expression in a rat glioma is conferred by two distinct hypoxia driven mechanisms. Cancer Res 1997;57:3860-3864.

22 Staller P, Sulitkova J, Lisztwan J, et al. Chemokine receptor CXCR4 downregulated by von Hippel-Lindau tumour suppressor pVHL. Nature 2003;425:307-311.

23 Zagzag D, Krishnamachary B, Yee H, et al. Stromal cellderived factor- $1 \alpha$ and CXCR4 expression in hemangioblastoma and clear cell-renal cell Carcinoma: von Hippel-Lindau loss-of-function induces expression of a ligand and its receptor. Cancer Res 2005;65: 6178-6188.

24 Olschwang S, Richard S, Boisson C, et al. Germline mutation profile of the VHL gene in von HippelLindau disease and in sporadic hemangioblastoma. Hum Mutat 1998;12:424-430.

25 Bleul CC, Farzan M, Choe H, et al. The lymphocyte chemoattractant SDF-1 is a ligand for LESTR/fusin and blocks HIV-1 entry. Nature 1996;382:829-833.

26 Burger JA, Kipps TJ. CXCR4: a key receptor in the cross talk between tumor cells and their microenvironment. Blood 2006;107:1761-1767.

$27 \mathrm{Su} \mathrm{L}$, Zhang J, Xu H, et al. Differential expression of CXCR4 is associated with the metastatic potential of human non-small cell lung cancer cells. Clin Cancer Res 2005;11:8273-8280.

28 Saur D, Seidler B, Schneider G, et al. CXCR4 expression increases liver and lung metastasis in a mouse model of pancreatic cancer. Gastroenterology 2005; 129:1237-1250.

29 Kang H, Watkins G, Douglas-Jones A, et al. The elevated level of CXCR4 is correlated with nodal metastasis of human breast cancer. Breast 2005;14: 360-367.

30 Cabioglu N, Sahin A, Doucet M, et al. Chemokine receptor CXCR4 expression in breast cancer as a potential predictive marker of isolated tumor cells in bone marrow. Clin Exp Metast 2005;22:39-46.

31 Rempel SA, Dudas S, Ge S, et al. Identification and localization of the cytokine SDF1 and its receptor, CXC chemokine receptor 4 , to regions of necrosis and angiogenesis in human glioblastoma. Clin Cancer Res 2000;6:102-111.

32 Oh JW, Drabik K, Kutsch O, et al. CXC chemokine receptor 4 expression and function in human astroglioma cells. J Immunol 2001;166:2695-2704.

33 Zhou Y, Larsen PH, Hao C, et al. CXCR4 is a major chemokine receptor on glioma cells and mediates their survival. J Biol Chem 2002;277:49481-49487.

34 Woerner BM, Warrington NM, Kung AL, et al. Widespread CXCR4 activation in astrocytomas revealed by phospho-CXCR4-specific antibodies. Cancer Res 2005; 65:11392-11399. 
35 Hong X, Jiang F, Kalkanis SN, et al. SDF-1 and CXCR4 are up-regulated by VEGF and contribute to glioma cell invasion. Cancer Lett 2006;236:39-45.

36 Ehtesham M, Winston JA, Kabos P, et al. CXCR4 expression mediates glioma cell invasiveness. Oncogene 2006;25:2801-2806.

37 Kleihues P, Louis DN, Scheithauer BW, et al. The WHO classification of tumors of the nervous system. J Neuropathol Exp Neurol 2002;61:215-225.

38 Gerlach OL, Skerlj RT, Brdiger GJ, et al. Molecular interactions of cyclam and bicyclam non-peptide antagonists with the CXCR4 chemokine receptor. J Biol Chem 2001;276:14153-14160.

39 von Marschall Z, Cramer T, Höcker TM, et al. Dual mechanism of vascular endothelial growth factor upregulation by hypoxia in human hepatocellular carcinoma. Gut 2001;48:87-96.

40 Liao W, Nguyen MT, Imamura T, et al. Lentiviral short hairpin ribonucleic acid-mediated knockdown of GLUT4 in 3T3-L1 adipocytes. Endocrinonology 2006; 147:2245-2252.

41 Zagzag D, Shiff B, Jallo GI, et al. Tenascin-C promotes microvascular cell migration and phosphorylation of focal adhesion kinase. Cancer Res 2002;62:2660-2668.

42 Schioppa T, Uranchimeg B, Saccani A, et al. Regulation of the chemokine receptor CXCR4 by hypoxia. J Exp Med 2003;198:1391-1402.

43 Bernards R. Cues for migration. Nature 2003;425: 247-248.

44 Kryczek I, Lange A, Mottram P, et al. CXCL12 and vascular endothelial growth factor synergistically induce neoangiogenesis in human ovarian cancers. Cancer Res 2005;65:465-472.

45 Marumo T, Schini-Kerth VB, Busse R. Vascular endothelial growth factor activates nuclear factorkappaB and induces monocyte chemoattractant protein-1 in bovine retinal endothelial cells. Diabetes 1999;48:1131-1137.

46 Salcedo R, Wasserman K, Young HA, et al. Vascular endothelial growth factor and basic fibroblast growth factor induce expression of CXCR4 on human en- dothelial cells: in vivo neovascularization induced by stromal-derived factor-1alpha. Am J Pathol 1999;154: 1125-1135.

47 Lee TH, Avraham H, Lee SH, et al. Vascular endothelial growth factor modulates neutrophil transendothelial migration via up-regulation of interleukin-8 in human brain microvascular endothelial cells. J Biol Chem 2002;277:10445-10451.

48 Abounader R, Laterra J. Scatter factor/hepatocyte growth factor in brain tumor growth and angiogenesis. Neuro-oncol 2005;7:436-451.

49 Matteucci E, Locati M, Desiderio MA. Hepatocyte growth factor enhances CXCR4 expression favoring breast cancer cell invasiveness. Exp Cell Res 2005; 310:176-185.

50 Tachibana K, Hirota S, Iizasa $\mathrm{H}$, et al. The chemokine receptor CXCR4 is essential for vascularization of the gastrointestinal tract. Nature 1998;393:591-594.

51 Guleng B, Tateishi K, Ohta M, et al. Blockade of the stromal cell-derived factor-1/CXCR4 axis attenuates in vivo tumor growth by inhibiting angiogenesis in a vascular endothelial growth factor-independent manner. Cancer Res 2005;65:5864-5871.

52 Volin MV, Joseph L, Shockley MS, et al. Chemokine receptor CXCR4 expression in endothelium. Biochem Biophys Res Commun 1998;242:46-53.

53 Mirshahi F, Pourtau J, Li H, et al. SDF-1 activity on microvascular endothelial cells: consequences on angiogenesis in in vitro and in vivo models. Thromb Res 2000;99:587-594.

54 Neuhaus T, Lutz C, Stier S, et al. The use of suppression subtractive hybridization for the study of SDF-1alpha induced gene-expression in human endothelial cells. Mol Cell Probes 2003;5:245-252.

55 Ceradini DJ, Kulkarni AR, Callaghan MJ, et al. Progenitor cell trafficking is regulated by hypoxic gradients through HIF-1 induction of SDF-1. Nat Med 2004;10:858-864.

56 Strieter RM, Belperio JA, Phillips RJ, et al. CXC chemokines in angiogenesis of cancer. Semin Cancer Biol 2004;4:195-200. 